\title{
Comparison of vegetable shortening and cocoa butter as vehicles for cortisol manipulation in Salmo trutta
}

Birnie-Gauvin, Kim; Peiman, K. S.; Larsen, M. H.; Aarestrup, Kim; Gilmour, K. M.; Cooke, S. J.

Published in:

Journal of Fish Biology

Link to article, DOI:

$10.1111 / \mathrm{jfb} .13513$

Publication date:

2018

Document Version

Peer reviewed version

Link back to DTU Orbit

Citation (APA):

Birnie-Gauvin, K., Peiman, K. S., Larsen, M. H., Aarestrup, K., Gilmour, K. M., \& Cooke, S. J. (2018).

Comparison of vegetable shortening and cocoa butter as vehicles for cortisol manipulation in Salmo trutta. Journal of Fish Biology, 92(1), 229-236. https://doi.org/10.1111/jfb.13513

\section{General rights}

Copyright and moral rights for the publications made accessible in the public portal are retained by the authors and/or other copyright owners and it is a condition of accessing publications that users recognise and abide by the legal requirements associated with these rights.

- Users may download and print one copy of any publication from the public portal for the purpose of private study or research.

- You may not further distribute the material or use it for any profit-making activity or commercial gain

- You may freely distribute the URL identifying the publication in the public portal 


\section{Comparison of vegetable shortening and cocoa butter as vehicles for cortisol manipulation}

in Salmo trutta

3

4 In press in Journal of Fish Biology

5

6 K. Birnie-Gauvin ${ }^{1 \dagger \S}$, K. S. Peiman ${ }^{1}$, M. H. Larsen ${ }^{3}$, K. Aarestrup ${ }^{4}$, K. M. Gilmour ${ }^{5}$, S. J. Cooke ${ }^{1}$ 7

$8 \quad{ }^{1}$ Fish Ecology and Conservation Physiology Laboratory, Department of Biology and Institute of 9 Environmental Science, Carleton University, 1125 Colonel By Drive, Ottawa, ON, Canada K1S $10 \quad 5 \mathrm{~B} 6$

$11{ }^{3}$ Danish Centre for Wild Salmon, Brusgårdsvej 15, 8960 Randers, Denmark.

$12{ }^{4}$ DTU AQUA, National Institute of Aquatic Resources, Section for Freshwater Fisheries and 13 Ecology, Technical University of Denmark, Vejlsøvej 39, 8600 Silkeborg, Denmark

$14{ }^{5}$ Department of Biology, University of Ottawa, 30 Marie-Curie, Ottawa, ON, Canada K1N 6N5 15 16

$17 \dagger$ Author to whom correspondence should be addressed:

$18 \quad$ Email: $\underline{\text { kbir@ aqua.dtu.dk, }}$ +45 35883114

$19 \S$ Change of address: K. Birnie-Gauvin, DTU Aqua, National Institute of Aquatic Resources, 20 Section for Freshwater Fisheries and Ecology, Technical University of Denmark, Vejlsøvej 39, 218600 Silkeborg, Denmark

22

23 Running headline: cortisol manipulation in fishes 


\section{ABSTRACT}

$25 \quad$ Vegetable shortening and cocoa butter have been used as vehicles for cortisol implants in 26 a wide range of organisms, though no studies have compared the effects of these vehicles on

27 plasma cortisol and glucose, or change in mass. This study demonstrates that vegetable

28 shortening and cocoa butter are two effective vehicles for intraperitoneal cortisol implants in

29 juvenile teleost fish (brown trout, Salmo trutta) residing in north temperate freshwater

30 environments. Each vehicle showed a different pattern of cortisol elevation. Vegetable

31 shortening was found to be a more suitable vehicle for long-term cortisol elevation (elevated at

32 days 3, 6 and 9 post-treatment), while cocoa butter may be better suited for short-term cortisol

33 elevation (only elevated at 3 days post-treatment). Additionally, plasma cortisol levels were

34 higher with cortisol-vegetable shortening than with cortisol-cocoa butter implants. Plasma

35 glucose levels were elevated 6 and 9 days post-treatment for fishes injected with cortisol-

36 vegetable shortening, but did not change relative to controls and shams in cortisol-cocoa butter

37 fishes. In conclusion, vegetable shortening and cocoa butter are both viable techniques for

38 cortisol manipulation in fishes in temperate climates, providing researchers with different options

39 depending on study objectives.

40

41 KEY WORDS: cocoa butter, cortisol implants, teleost fish, vegetable shortening 


\section{INTRODUCTION}

Cortisol is the primary glucocorticoid stress hormone in fish (Mommsen et al., 1989;

49 Wendelaar Bonga, 1997; Barton, 2002). Not surprisingly, there are hundreds of papers that have

50 measured cortisol in fishes to understand the consequences of different stressors (reviewed in

51 Mommsen et al., 1999). Beyond using cortisol as a biomarker of exposure to a stressor,

52 physiologists started manipulating cortisol in fishes in the 1960 s to explore the mechanistic role

53 of cortisol (e.g., Slusher, 1966). This allowed researchers to move past simply observing

54 variation in cortisol levels among individuals to performing cause-and-effect studies. However,

55 despite its potential ecological relevance (Sopinka et al., 2015; Crossin et al., 2016), this

56 technique has been mainly used in the lab (reviewed in Gamperl et al., 1994). Additionally, the

57 best vehicle in which to suspend the cortisol for manipulation remains unclear. Past studies have

58 used saline oil (e.g. coconut oil), cocoa butter, and vegetable shortening to manipulate hormone

59 levels (Pottinger \& Pickering, 1985; Gamperl et al., 1994; Eriksen et al., 2006; Doyon et al.,

60 2006). Studies have also used mini osmotic pumps going back several decades (Theeuwes \&

61 Yum, 1976). However, these are less suitable for field studies owing to expense, as fish may not

62 be recovered to retrieve the pumps, and their higher invasiveness compared to injections. The

63 main advantage of cocoa butter and vegetable shortening is that they allow for prolonged,

64 continuous release of cortisol. They are injected as liquids, and solidify once inside the fish.

65 However, cocoa butter requires high temperatures to remain in liquid form (approx. $40^{\circ} \mathrm{C}$ ),

66 potentially resulting in the scalding of organs when injected into a fish, and becomes very hard at

67 ambient temperatures in the north temperate regions which may lead to damage to the gonads

68 (personal observation; McConnachie et al., 2012). In contrast, vegetable shortening remains in

69 liquid form at a lower temperature (approx. $30^{\circ} \mathrm{C}$ ), and remains soft, even in cold water $\left(5^{\circ} \mathrm{C}\right.$, 
70 personal observation). Gamperl et al. (1994) originally suggested that vegetable shortening was

71 better than cocoa butter at lower temperatures as the hardness of cocoa butter may reduce the

72 absorption of cortisol.

73 This study is the first comparative study of vegetable shortening and cocoa butter as

74 vehicles for cortisol manipulation in the wild. Both vehicles are particularly suitable for field

75 studies (see Sopinka et al., 2015) owing to their low cost and ease of administration. A wild

76 population of juvenile brown trout Salmo trutta L. 1758 was used to compare the temporal

77 patterns of circulating cortisol and glucose concentrations resulting from implants of cortisol

78 suspended in vehicles of cocoa butter versus vegetable shortening. Treatment effects were

79 compared to their corresponding sham (vehicle alone) and control (no implant) groups.

80 Additionally, effects on body mass were measured treatment. It was predicted that vegetable

81 shortening implants would result in cortisol being released over a longer period of time and in

82 higher levels, resulting in higher levels of glucose and more mass loss than cocoa butter

83 implants. It was also predicted that sham treatments would not elevate cortisol or glucose

84 concentrations or cause a change in mass compared to control fishes.

85

86 MATERIALS AND METHODS

87 The Villestrup stream is located in north-central Jutland, Denmark. The stream runs for several

88 kilometers across agricultural land, where a number of tributaries join in before reaching the

89 Mariager Fjord. The stream is home to a large population of semi-anadromous S. trutta (del

90 Villar-Guerra et al., 2014). Three different sites (1 to $2 \mathrm{~km}$ apart) within the same stream were

91 used. It is unlikely that there are genetic differences among populations so close (Hansen et al.,

92 2002), but even if there are, they are unlikely to have any biological significance especially when 
93 comparing responses to treatments within a site. Fishes were captured via backpack

94 electrofishing (ELT 60 II GI; 300 volts; Scubla, Remanzacco, Italy) on three separate days in

95 2016: 125 fishes at Site 1 on March $3^{\text {rd }}$ (25 fishes per group), 125 fishes at Site 2 on March $4^{\text {th }}$

96 (25 fishes per group) and 150 fishes at Site 3 on March $5^{\text {th }}$ (30 fishes per group). During this

97 period, the temperature of the water in Villestrup was between 6 and $7^{\circ} \mathrm{C}$.

$98 \quad$ Captured fishes were held in a 601 bin filled with oxygenated fresh stream water. Fishes

99 were anesthetized in a solution of benzocaine $\left(0.03 \mathrm{~g} \mathrm{l}^{-1}\right.$ ethyl-p-aminobenzoate; Sigma,

100 www.sigmaaldrich.com) in stream water, then weighed $( \pm 0.1 \mathrm{~g})$, measured for total length

$101( \pm 0.1 \mathrm{~cm})$, and tagged using a 23mm PIT tag (Passive Integrated Transponder tag, Texas

102 Instruments, RI-TRP-RRHP, 134Hz, 0.6g mass in air, Plano, Texas, USA). Tags were inserted

103 through a $5 \mathrm{~mm}$ incision in the left side of the body, posterior to the pelvic fin. Only trout that

104 were $12-21 \mathrm{~cm}$ in length (large enough for the PIT tag, but likely still juveniles; Larsen et al.

105 2013) were used in this study. Fishes were randomly assigned to one of the following treatment

106 groups: (1) control, (2) sham-vegetable shortening (sham-veg), (3) cortisol-vegetable shortening

107 (cort-veg), (4) sham-cocoa butter (sham-cocoa), (5) cortisol-cocoa butter (cort-cocoa). Cortisol-

108 treated fishes received an intracoelomic injection (1.5inch 18-gauge needle) of a suspension of

109 vegetable shortening (100\% vegetable shortening, Crisco, OH, USA) or cocoa butter (100\% pure

110 cocoa butter, NOW Foods, IL, USA) mixed with hydrocortisone 21-hemisuccinate (Sigma-

111 Aldrich, St. Louis, MO, USA, Product \#H2882-1G), using a dosage of $0.01 \mathrm{ml}$ vehicle (with a

112 concentration of $0.01 \mathrm{~g}$ cortisol per $\mathrm{ml}$ ) per $1 \mathrm{~g}$ of fish (equivalent to a cortisol dosage of $100 \mathrm{mg}$

$113 \mathrm{~kg}^{-1}$ ). Sham fishes were injected with only $0.01 \mathrm{ml} \mathrm{g}^{-1}$ fish vegetable shortening or cocoa butter.

114 The vegetable shortening and cocoa butter were heated using hot water to a temperature of $37^{\circ} \mathrm{C}$

115 and $40{ }^{\circ} \mathrm{C}$, respectively. All fishes were recovered (i.e., until full equilibrium was reached) in a 
116601 tank of benzocaine-free fresh stream water following tagging. Cortisol-treated fishes were

117 recovered separately from sham and control fishes to prevent any cross-treatment contamination

118 of cortisol, and all fishes were then released at the site of capture. The tagging, weighing,

119 measuring and injecting process took less than one minute per fish. Overall, fishes were held in 120 tanks for approximately 60 minutes.

121 Fishes were recaptured via backpack electrofishing after 3, 6 and 9 days post-treatment, 122 at Site 3, Site 2 and Site 1, respectively. Immediately after shocking, we collected a blood sample

$123(<0.3 \mathrm{ml})$ from the caudal vasculature using a heparinized 1.5-inch 25-gauge needle and a $1 \mathrm{ml}$

124 syringe. All samples were collected within 3 minutes of capture. Fishes were then weighed.

125 Following recovery, fishes were returned to the river, and not recaptured. Blood samples were

126 held in a water-ice slurry until centrifuged at $2000 \mathrm{~g}$ for 2 minutes to separate plasma from red

127 blood cells. Plasma samples were kept at $-80^{\circ} \mathrm{C}$ until analyzed. Environmental conditions should

128 not be a confounding factor here, as the 3 day sampling was within the 6 day sampling, and both

129 were within the 9 day sampling period. Hence, all fishes were exposed to the same conditions,

130 with day 9 fishes potentially experiencing a greater variation. However, this does not affect

131 treatment effects within a single time point, which is the focus of this study.

132 Plasma cortisol concentration was determined using a commercial radioimmunoassay kit

133 (ImmunoChem Cortisol ${ }^{125}$ I RIA kit; MP Biomedicals, www.mpbio.com). This assay was

134 previously validated for use with teleost fish plasma samples (Gamperl et al., 1994). All plasma

135 samples were measured in a single assay. Intra-assay variability (\%CV) was 7.9\%. Plasma

136 glucose levels were determined using an AccuCheck Compact Plus meter system (Roche, Basel,

137 Switzerland), a point-of-care device previously validated for use in teleost fishes (Stoot et al., 138 2014). 
140 Buckinghamshire, UK). Cortisol and glucose values were log-transformed to achieve normality

141 of residuals. Two-way ANOVAs were used to evaluate differences in cortisol, glucose and

142 change in mass among treatment groups over the three sampling times. A Tukey-Kramer post-

143 hoc test was used to determine which groups differed, which is conservative with unequal

144 sample sizes as is the case here. Spearman correlations (to reduce the effect of outliers) were

145 used to determine whether cortisol levels were related to glucose levels among individuals using

146 within each category of treatment and day.

\section{RESULTS}

149 Between 9 and 17 fishes were recaptured per treatment group. Fishes treated with cortisol 150 suspended in vegetable shortening showed significantly higher plasma cortisol concentrations

151 after 3, 6 and 9 days post-treatment than both sham and the control treatments, with values at day

1523 significantly higher than at day 9 (Fig. $1 \mathrm{~A}$; treatment $\times$ time, $\left.\mathrm{F}_{8,172}=3.07, P=0.0029\right)$. Cort-

153 cocoa fishes at day 3 had significantly higher cortisol levels than both sham and the control

154 treatments, but values for fishes sampled at days 6 and 9 did not differ from those for sham or

155 control fishes. At day 3, cort-veg fishes exhibited significantly higher plasma cortisol levels than

156 cort-cocoa fishes. Cortisol concentrations for fishes in the sham treatment were similar to fishes

157 in the control group across all time points. Glucose concentrations in cort-veg fishes were

158 significantly higher than those for sham and control treatments at days 6 and 9 (Fig. 1B;

159 treatment $\times$ time, $\mathrm{F}_{8,170}=2.30, P=0.023$ ), whereas plasma glucose concentrations in cort-cocoa

160 fishes did not differ from the sham or control groups on any day. On days 6 and 9, cort-veg

161 fishes had significantly higher glucose concentrations than cort-cocoa fishes. 
Initially, mass for cortisol-treated fishes did not differ from their sham or the control

163 group (all $P>0.50$ ). Sham-veg fishes sampled on day 9 gained mass while all other groups lost

164 mass (Fig 1C, treatment $\times$ time, $\left.\mathrm{F}_{8,170}=2.94, P=0.0042\right)$.

165 Plasma cortisol and glucose concentrations were positively related in day 9 cort-veg

166 treatment $\left(\mathrm{R}^{2}=0.60, \mathrm{n}=15, P=0.037\right)$ No other correlation was significant (all $\left.P>0.093\right)$.

\section{DISCUSSION}

169 Cortisol implants $\left(100 \mathrm{mg} \mathrm{kg}^{-1}\right)$ generated a significant elevation in plasma cortisol

170 concentration using either vegetable shortening or cocoa butter as a vehicle. However, the use of

171 vegetable shortening as a vehicle caused a greater elevation of cortisol concentration than cocoa

172 butter after 3 days, and this elevation lasted longer. Moreover, plasma cortisol concentration

173 likely remained high for more than 9 days in fishes that received cortisol-vegetable shortening

174 implants, as found by Pickering \& Duston (1983). In contrast, cocoa butter implants had short-

175 lasting effects on plasma cortisol levels, with circulating concentrations returning to control

176 levels by 6 days post-treatment. The soft texture of vegetable shortening (Fig. 2), even at low

177 temperatures (solidifies at $20^{\circ} \mathrm{C}$, but remains soft at lower temperatures - e.g., it was $6-7^{\circ} \mathrm{C}$

178 during this study) likely allows for more effective (i.e., faster) release of the cortisol. Cocoa

179 butter, however, becomes very hard even at fairly high temperatures (solidifies at $20^{\circ} \mathrm{C}$ ), which

180 may prevent long-lasting release of cortisol in north temperate fish species, as indicated by the

181 peak cortisol levels 3 days post-treatment. The outer cortisol likely gets released quickly, but the

182 hardness of the cocoa butter prevents the release of the inner cortisol. Alternatively, it is possible

183 that cocoa butter releases cortisol more readily than vegetable shortening, leading to the implant

184 being depleted of cortisol more rapidly and the cortisol values in cocoa butter-treated fishes 
185 peaking earlier than the first sampling time (3 days). Unfortunately, there is no way to

186 distinguish between the two possibilities with our data. The conclusion however, remains the

187 same: vegetable shortening appears to be a more appropriate vehicle for studies seeking long-

188 term cortisol elevation, while cocoa butter may be better suited for short-term cortisol elevation,

189 at least in north temperate regions.

190 Cortisol increases the rate of gluconeogenesis (reviewed by Mommsen et al., 1999). An

191 increase in plasma glucose following treatment with cortisol implants therefore would be

192 consistent with the known physiological effects of cortisol. Plasma glucose concentrations were

193 found to be higher than those of sham and control treatments at both day 6 and 9 in cort-veg

194 fishes. In contrast, plasma glucose was never elevated above sham or control treatment fishes in

195 cort-cocoa fishes, in agreement with the shorter-lasting physiological effect of cocoa butter than

196 vegetable shortening on cortisol levels. Additionally, cortisol caused an increase in glucose

197 levels earlier in the cort-cocoa treatment (day 3) than in the cort-veg treatment (day 9), further

198 supporting the hypothesis that the cocoa butter vehicle generates a shorter and faster response

199 than vegetable shortening.

200 Increased conversion of stored energy reserves to glucose during gluconeogenesis may

201 also lead to a loss in mass. Additionally, cortisol tends to suppress appetite leading to a reduction

202 in food intake, and this would also be expected to result in mass loss (Madison et al., 2015). The

2039 days of the cortisol treatment examined in the present study did not have a significant effect on

204 change in mass relative to that observed in control or sham-treated fishes, suggesting that the

205 physiological effects of elevated cortisol take more time to manifest as changes in mass.

206 Previous studies in similar systems have reported decreased growth rates of cortisol-treated

207 fishes over two weeks and longer (Madison et al., 2015; Midwood et al., 2015; Midwood et al., 
208 2016; Birnie-Gauvin et al., 2017; Peiman et al., 2017). Sham-veg fishes at day 9 showed a

209 significant increase in mass, which may have resulted from the vegetable shortening itself

210 starting to be absorbed internally, while in the cort-veg fishes this effect may have been offset by

211 glucose metabolized by cortisol. Indeed, it was only in this latter group that cortisol and glucose

212 were positively related. The mechanism by which this occurred is unknown and its biological

213 significance remains evasive.

214 The present study showed that vegetable shortening and cocoa butter are two effective

215 vehicles for cortisol implants in north temperate regions, and that sham treatments with the

216 vehicle alone do not result in growth impairments compared to controls over the short-term, as

217 previously observed in reproductive female $S$. trutta following cocoa butter sham implants

218 (Hoogenboom et al., 2011). However, it was noticed that cocoa butter implants had sharp edges,

219 which could result in internal organ damage, a potentially deleterious effect which has not

220 previously been noted. Cortisol levels peaked 3 days post-treatment for both vegetable

221 shortening and cocoa butter implants, and cortisol levels remained elevated for 9 days with the

222 vegetable shortening implant. Maximum cortisol levels achieved in this experiment are beyond

223 the physiological range for salmonids (Donaldson, 1981; Gamperl et al., 1994). If the goal of the

224 study requires cortisol levels within the normal physiological range, a lower dosage of cortisol

225 may be appropriate. Glucose levels were affected by cortisol in fishes that received vegetable

226 shortening but not cocoa butter implants. Thus, in north temperate regions, vegetable shortening

227 is a more appropriate vehicle for studies seeking longer-term cortisol elevation, while cocoa

228 butter may be better suited for studies looking for short-term cortisol elevation, providing

229 researchers with different options depending on study objectives. 
231 S. J. Cooke is supported by the Canada Research Chairs Program, the NSERC E.W.R. Steacie

232 Memorial Fellowship and the NSERC Discovery Grant (DG) program. This study was also

233 partly funded by the Danish Rod and Net Fish License Funds, and by NSERC DG funding to K.

234 M. Gilmour. We thank J. S. Mikkelsen, M. Holm, H. -J. Christensen, A. Garcia Laborde and F.

235 Valenzuela Aguayo for assisting us in the field. We also thank M. -E. Bélair Bambrick and C.

236 Best for their help in the lab.

237

238 REFERENCES

239

240 Barton, B. A. (2002). Stress in fishes: a diversity of responses with particular reference to

241 changes in circulating corticosteroids. Integrative and Comparative Biology 42, 517-525. doi:

$242 \quad 10.1093 / \mathrm{icb} / 42.3 .517$

243

244 Birnie-Gauvin, K., Peiman, K. S., Larsen, M. H., Aarestrup, K., Willmore, W. G., Cooke, S. J.

245 (2017). Short-term and long-term effects of transient exogenous cortisol manipulation on

246 oxidative stress in juvenile brown trout. Journal of Experimental Biology 220, 1693-1700. doi:

$247 \quad 10.1242 /$ jeb. 155465

248

249 Crossin, G. T., Love, O. P., Cooke, S. J., \& Williams, T. D. (2016). Glucocorticoid

250 manipulations in free-living animals: considerations of dose delivery, life-history context and

251 reproductive state. Functional Ecology 30, 116-125. doi: 10.1111/1365-2435.12482

252 
253 del Villar-Guerra, D., Aarestrup, K., Skov, C., Koed, A. (2014). Marine migrations in

254 anadromous brown trout (Salmo trutta). Ecology of Freshwater Fish 23, 594-603. doi:

255 10.1111/eff.12110

256

257 Donaldson, E. M. (1981). Pituitary-interrenal axis as an indicator of stress in fish. In Stress and

258 Fish (Pickering, A. D., eds), pp. 11-47. London and New York: Academic Press.

259

260 Doyon, C., Leclair, J., Trudeau, V. L., Moon, T. (2006). Corticotropin-releasing factor and 261 neuropeptide Y mRNA levels are modified by glucocorticoids in rainbow trout, Oncorhynchus 262 mykiss. General and Comparative Endocrinology 146, 126-135. doi:

263 10.1016/j.ygcen.2005.10.003

264

265 Eriksen, M. S., Bakken, M., Espmark, Å., Braastad, B. O., Salte, R. (2006). Prespawning stress

266 in farmed Atlantic salmon Salmo salar: maternal cortisol exposure and hyperthermia during

267 embryonic development affect offspring survival, growth and incidence of malformations.

268 Journal of Fish Biology 69, 114-129. doi: 10.1111/j.1095-8649.2006.01071.x

269

270 Gamperl, A. K., Vijayan, M. M., Boutilier, R. G. (1994). Experimental control of stress hormone

271 levels in fishes: techniques and applications. Reviews of Fish Biology and Fisheries 4, 215-255.

272 doi: $10.1007 / \mathrm{BF} 00044129$

273

274 Hansen, M. M., Ruzzante, D. E., Nielsen, E. E., Bekkevold, D., Mensberg, K. L. D. (2002).

275 Long-term effective population sizes, temporal stability of genetic composition and potential for 
276 local adaptation in anadramous brown trout (Salmo trutta) populations. Molecular Ecology 11,

277 2523-2535. doi: 10.1046/j.1365-294X.2002.01634.x

278

279 Hoogenboom, M. O., Armstrong, J. D., Miles, M. S., Burton, T., Groothuis, T. G., Metcalfe, N. 280 B. (2011). Implantation of cocoa butter reduces egg and hatchling size in Salmo trutta. Journal 281 of Fish Biology 79, 587-596. doi: 10.1111/j.1095-8649.2011.03039.x

282

283 Larsen, M. H., Thorn, A. N., Skov, C., Aarestrup, K. (2013). Effects of passive integrated 284 transponder tags on survival and growth of juvenile Atlantic salmon, Salmo salar. Animal 285 Biotelemetry 1, 19-25. doi: 10.1186/2050-3385-1-19

287 Madison, B. N., Tavakoli, S., Kramer, S., Bernier, N. J. (2015). Chronic cortisol and the 288 regulation of food intake and the endocrine growth axis in rainbow trout. Journal of

289 Endocrinology 226, 103-119. doi: 10.1530/JOE-15-0186

290

291 McConnachie, S. H., Cook, K. V., Patterson, D. A., Gilmour, K. M., Hinch, S. G., Farrell, A. P., 292 Cooke, S. J. (2012). Consequences of acute stress and cortisol manipulation on the physiology, 293 behavior and reproductive outcome of female Pacific salmon on spawning grounds. Hormones 294 and Behaviour 62, 67-76. doi: 10.1016/j.yhbeh.2012.05.001

295

296 Midwood, J. D., Larsen, M. H., Boel, M., Aarestrup, K., Cooke, S. J. (2015). An experimental 297 field evaluation of winter carryover effects in semi-anadromous brown trout (Salmo trutta).

298 Journal of Experimental Zoology 323, 645-654. doi: 10.1002/jez.1955 
300 Midwood, J. D., Larsen, M. H., Aarestrup, K., Cooke, S. J. (2016). Stress and food deprivation:

301 linking physiological state to migration success in a teleost fish. Journal of Experimental Biology

302 219, 3712-3718. doi: 10.1242/jeb.140665

303

304 Mommsen, T. P., Vijayan, M. M., Moon, T. W. (1999). Cortisol in teleosts: dynamics, 305 mechanisms of action, and metabolic regulation. Reviews in Fish Biology and Fisheries 9, 211306 268. doi: 10.1023/A:1008924418720

307

308 Peiman, K. S., Birnie-Gauvin, K., Midwood, J. D., Larsen, M. H., Wilson, A. D., Aarestrup, K., 309 Cooke, S. J. (2017). If and when: intrinsic differences and environmental stressors influence 310 migration in brown trout (Salmo trutta). Oecologia 184, 374-384. doi: 10.1007/s00442-017$311 \quad 3873-9$

312

313 Pickering, A. D., Duston, J. (1983). Administration of cortisol to brown trout, Salmo trutta L., 314 and its effects on the susceptibility to Saprolegnia infection and furunculosis. Journal of Fish 315 Biology 23, 163-175. doi: 10.1111/j.1095-8649.1983.tb02891.x

317 Pottinger, T. G., Pickering, A. D. (1985). The effects of 11-ketotestosterone and testosterone on 318 the skin structure of brown trout, Salmo trutta L. General and Comparative Endocrinology 59, 319 335-342. doi: 10.1016/0016-6480(85)90389-2 
321 Slusher, M. A. (1966). Effects of cortisol implants in the brainstem and ventral hippocampus on

322 diurnal corticosteroid levels. Experimental Brain Research 1, 184-194. doi:

$32310.1007 / \mathrm{BF} 00236870$

324

325 Sopinka, N. M., Patterson, L. D., Redfern, J. C., Pleizier, N. K., Belanger, C. B., Midwood, J. D.,

326 Crossin, G. T., Cooke, S. J. (2015). Manipulating glucocorticoids in wild animals: basic and

327 applied perspectives. Conservation Physiology 3, cov031. doi:10.1093/conphys/cov031

328

329 Stoot, L. R., Cairns, N. A., Cull, F., Taylor, J. J., Jeffrey, J. D., Morin, F., Mandelman, J. W.,

330 Clark, T. D., Cooke, S. J. (2014). Use of portable blood physiology point-of-care devices for

331 basic and applied research on vertebrates: a review. Conservation Physiology 2, cou011.

332 doi: 10.1093/conphys/cou011

333

334 Theeuwes, F., Yum, S. I. (1976). Principles of the design and operation of generic osmotic

335 pumps for the delivery of semisolid and liquid drug formulations. Annals of Biomedical

336 Engineering 4, 343-353. doi: 10.1007/BF02584524

337

338 Wendelaar Bonga, S. E. W. (1997). The stress response in fish. Physiological Reviews 77, 591-

339 625. doi: 10.0031-9333/97

340

341

342

343 


\section{FIGURE CAPTIONS}

346 Fig 1. PIT-tagged brown trout (Salmo trutta) were subjected to one of 5 treatments; control (no

347 implant), sham-veg (given a vegetable shortening implant), sham-cocoa (given a cocoa butter

348 implant), cort-veg (given $100 \mathrm{mg} \mathrm{kg}^{-1}$ of cortisol suspended in a vegetable shortening implant)

349 and cort-cocoa (given $100 \mathrm{mg} \mathrm{kg}^{-1}$ of cortisol suspended in a cocoa butter implant), and were re-

350 captured at 3 (black bars), 6 (grey bars) or 9 (white bars) days post-treatment. (A) Plasma

351 cortisol concentration, (B) plasma glucose concentration, and (C) change in mass are presented

352 as a function of treatment group and sampling day. Values are means + SEM, $N=9$ to 17 .

353 Groups that share a letter are not significantly different from one another (see text for details).

355 Fig 2. Representative images of the dissection of brown trout (Salmo trutta) post-treatment to 356 illustrate the different implant vehicles; (A) control, (B) vegetable shortening implant, and (C) 357 cocoa butter implant. Arrows point to the implants. Vegetable shortening remained soft at 3, 6 358 and 9 days post-treatment. Cocoa butter implants were hard to the touch at 3,6 and 9 days post359 treatment, with some implants showing sharp edges. 
Figure 1.
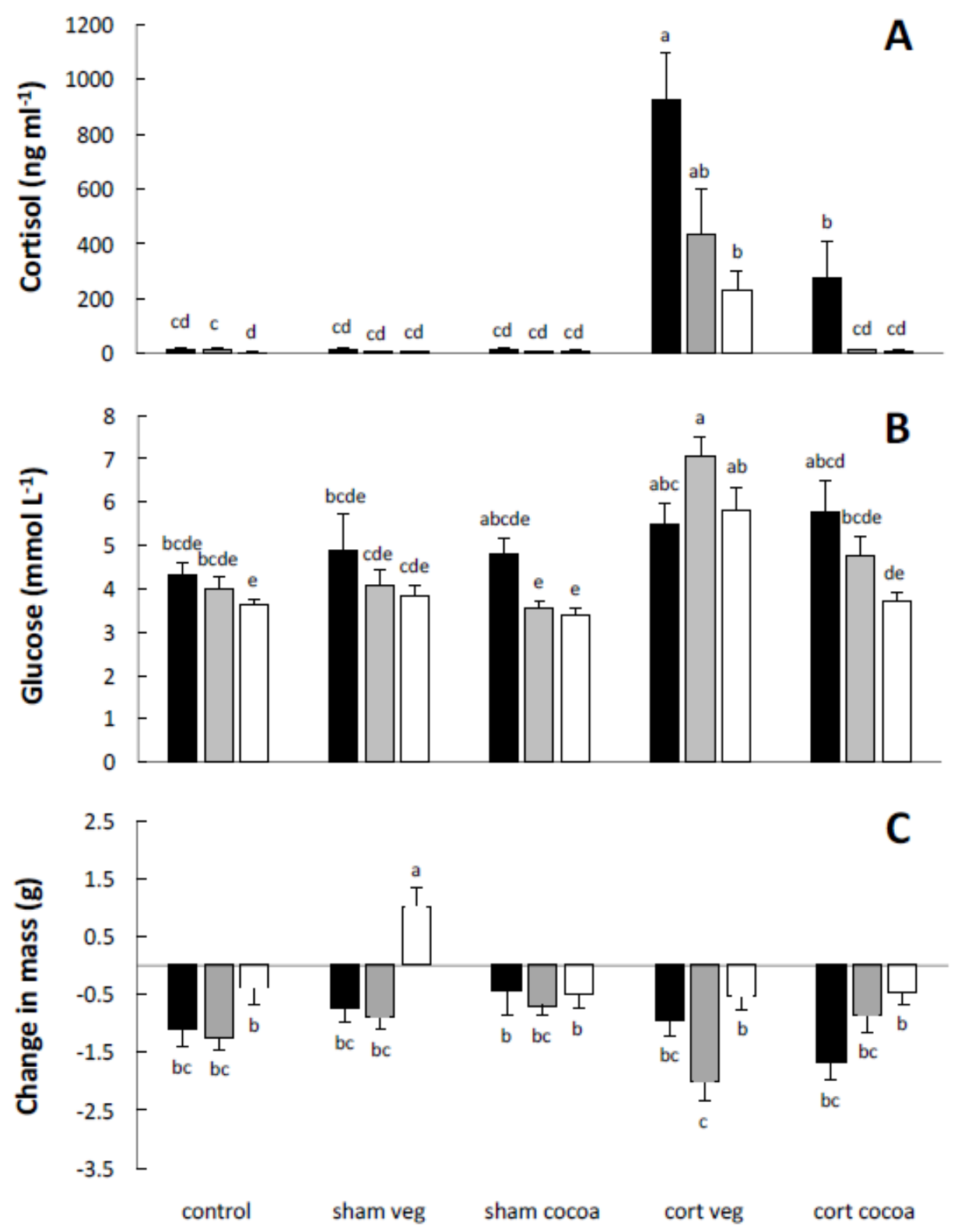

Treatment 
372 Figure 2.

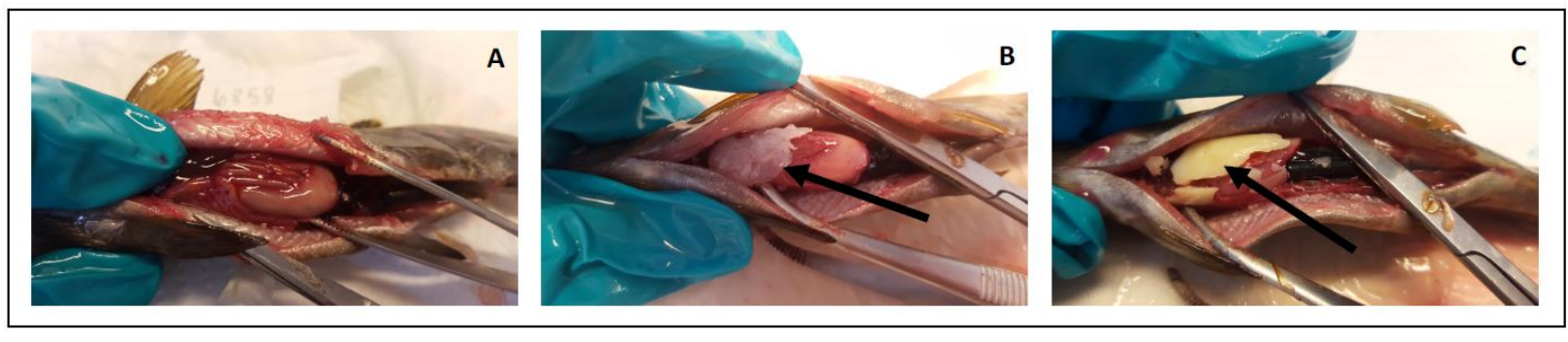

373 